\title{
Role of columnar cell lesions in breast carcinogenesis: analysis of chromosome 16 copy number changes by multiplex ligation-dependent probe amplification
}

\author{
Mirthe de Boer ${ }^{1} \cdot$ Anoek H. J. Verschuur-Maes ${ }^{2} \cdot$ Horst Buerger $^{3} \cdot{\text { Cathy B Moelans } \mathbb{D}^{1} \cdot \text { Maryvonne Steenkamer }}^{4}$. \\ Suvi Savola $\mathbb{( i D}^{4} \cdot$ Paul J. van Diest ${ }^{1}$
}

Received: 10 November 2017 / Revised: 31 May 2018 / Accepted: 1 June 2018 / Published online: 5 July 2018

(c) United States \& Canadian Academy of Pathology 2018

\begin{abstract}
Columnar cell lesions have been proposed as precursor lesions of low-grade breast cancer. The molecular characteristic of low-grade breast neoplasia is whole-arm loss of chromosome 16q. Copy number changes of 6 genes on 16p and 20 genes on 16q were analysed by multiplex ligation-dependent probe amplification in 165 lesions of 103 patients. Twenty-three columnar cell lesions and 19 atypical ducal hyperplasia lesions arising in columnar cell lesions were included, as well as cases of usual ductal hyperplasia, blunt duct adenosis, ductal carcinoma in situ, lobular neoplasia and invasive carcinoma. Usual ductal hyperplasia and blunt duct adenosis lacked whole-arm losses of 16q. In contrast, columnar cell lesions without atypia, columnar cell lesions with atypia, atypical ductal hyperplasia, low-grade ductal carcinoma in situ and low-grade invasive carcinomas increasingly harboured whole-arm losses of $16 \mathrm{q}(17 \%, 27 \%, 47 \%$ and $57 \%$, respectively). However, no recurrent losses in specific genes could be identified. In several patients, columnar cell lesions and atypical ductal hyperplasia harboured similar losses as related ductal carcinoma in situ or invasive carcinomas within the same breast. There were indications for 16q breakpoints near the centromere. Whole-arm gains on 16p were relatively scarce and there was no relation between whole-arm gains of 16p and progression of lesions of the low-grade breast neoplasia family. In conclusion, columnar cell lesions (with and without atypia) often harbour whole-arm losses of 16q, which underlines their role as precursors in low-grade breast carcinogenesis, in contrast with usual ductal hyperplasia and blunt duct adenosis. However, no recurrent losses in specific genes could be identified, pointing to minor events in multiple tumour suppressor genes rather than major events in a single $16 \mathrm{q}$ gene contributing to low-grade breast carcinogenesis.
\end{abstract}

\section{Introduction}

Columnar cell lesions of the breast are cystically dilated enlarged terminal duct lobular units lined by columnar cells often with apical cytoplasmic blebs or snouts present at the

Electronic supplementary material The online version of this article (https://doi.org/10.1038/s41379-018-0099-2) contains supplementary material, which is available to authorized users.

Paul J. van Diest

p.j.vandiest@umcutrecht.nl

1 Department of Pathology, University Medical Center Utrecht, Heidelberglaan 100, 3584 CX Utrecht, The Netherlands

2 Gelre Hospitals, Apeldoorn, The Netherlands

3 Institute of Pathology, Paderborn, Germany

4 MRC-Holland, Amsterdam, The Netherlands luminal surface. The lining consists of one or two (columnar cell change), or more (columnar cell hyperplasia) cell layers. Intraluminal secretions and microcalcifications are frequently seen [1]. In columnar cell lesions with atypia, the columnar cells show nuclear atypia of relatively round to ovoid, sometimes irregular nuclei with prominent nucleoli and an increased nuclear/cytoplasmic ratio. In addition, the nuclear orientation along the basement membrane can be disturbed. Complex architectural patterns upgrade a columnar cell lesion to atypical ductal hyperplasia or lowgrade ductal carcinoma in situ $[2,3]$. Columnar cell lesions with atypia have also been denoted flat epithelial atypia [2]. In recent years it has been recognized that columnar cell lesions have a possible role as precursor of low nuclear grade breast cancer [4-6].

Multiple studies on chromosome 16 aberrations in breast cancer have shown an association between loss of the long arm of chromosome 16 [16q] and low-grade breast cancer 
[7-13]. These losses of chromosome 16q have also been reported in premalignant lesions, such as atypical ductal hyperplasia, low-grade ductal carcinoma in situ and lobular neoplasia [14-22]. Thereby, this chromosomal aberration is probably one of the first steps in low-grade carcinogenesis.

Several authors have investigated aberrations on chromosome 16 in columnar cell lesions by loss of heterozygosity analysis, (array) comparative genomic hybridization or fluorescent in situ hybridization [5, 6, 23-26]. The results of these studies vary strongly (see Table 1), most likely due to the small number of tested lesions, different types of columnar cell lesions studied and use of different DNA probes, varying definitions of columnar cell lesions and inter-observer variability in diagnosing columnar cell lesions $[27,28]$. In addition, the presence of whole-arm loss in columnar cell lesions was never reported, suggesting that these results might be incomplete.

Therefore, in this study we investigated in depth copy number changes of 21 genes on 16q and 6 genes on 16p in columnar cell lesions, and other lesions of the low-nucleargrade breast neoplasia family (atypical ductal hyperplasia, ductal carcinoma in situ, invasive ductal carcinoma, lobular neoplasia and invasive lobular carcinoma). In addition, high-nuclear-grade (pre)malignant lesions (ductal carcinoma in situ and invasive ductal carcinoma) and benign, columnar cell-like lesions (usual ductal hyperplasia and blunt duct adenosis) were analysed. To our knowledge, this is the first study investigating copy number changes of multiple genes on chromosome 16q (and 16p) in a relatively large group of columnar cell lesions with and without atypia, as well as related lesions. In addition, this is the first study describing the presence of whole-arm losses of $16 \mathrm{q}$ in columnar cell lesions.

\section{Methods}

\section{Patient material}

From formalin-fixed, paraffin-embedded breast resection specimens, tissue samples with columnar cell-like lesions (usual ductal hyperplasia and blunt duct adenosis), columnar cell lesions (with or without atypia) and atypical ductal hyperplasia (consisting of columnar cells with apical snouts and complex architecture, so probably originating form a columnar cell lesion) were collected between 1996 and 2013 at the Departments of Pathology of the University Medical Center, Utrecht, and St. Antonius Hospital Nieuwegein, The Netherlands. Vacuum biopsies and core needle biopsies were excluded. If present and available for DNA analysis, co-existing lesions such as lobular neoplasia, ductal carcinoma in situ and invasive carcinoma were also included. All ductal carcinoma in situ and invasive

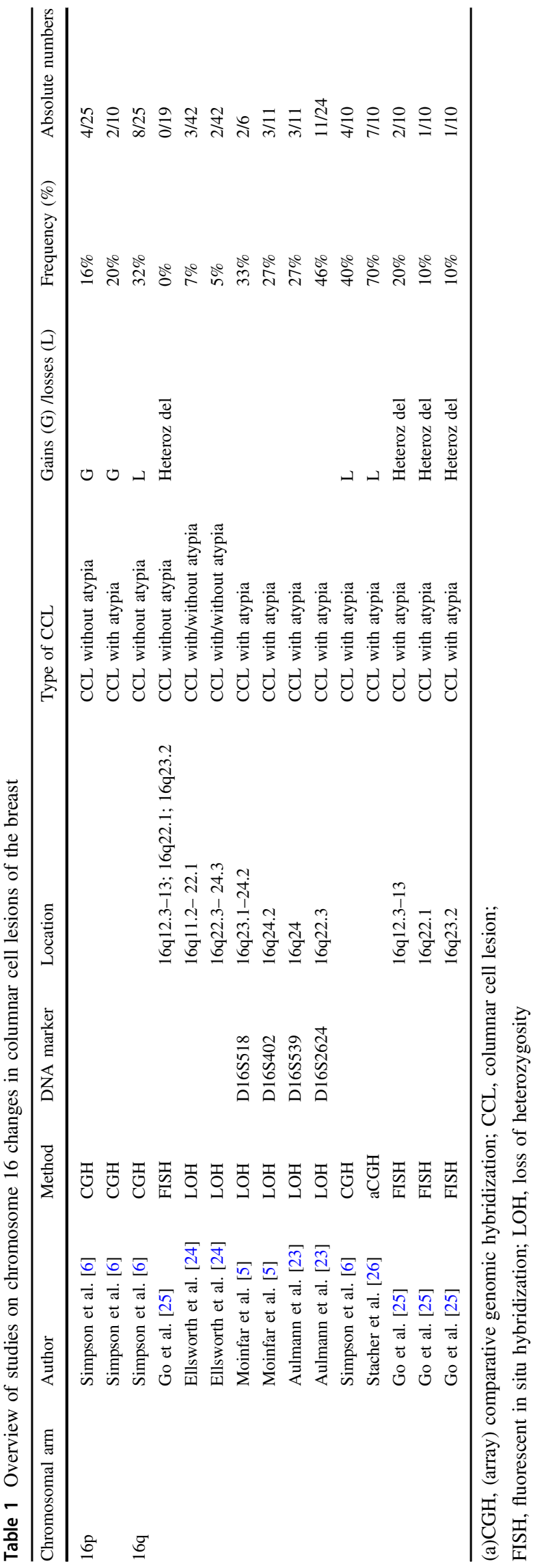


carcinoma subgroups (ductal carcinoma in situ/invasive ductal carcinoma grades 1,2 and 3, tubular carcinomas and invasive lobular carcinoma non-pleomorphic type) were supplemented to groups of at least 10 cases each.

The columnar cell lesions were graded according to the classification described by Schnitt and Vincent-Salomon [3] as columnar cell lesions without atypia and columnar cell lesions with atypia. Classification and grading of the invasive carcinoma [29, 30], ductal carcinoma in situ [31], atypical ductal hyperplasia [32], usual ductal hyperplasia [33] and lobular neoplasia [34] was assessed by two experienced observers ( $\mathrm{PvD}$ and $\mathrm{MdB}$ ), according to the World Health Organization classification. For differentiation between lobular neoplasia and atypical ductal hyperplasia, e-cadherin immunohistochemical staining was used. Blunt duct adenosis was classified according to descriptions of Lerwill [35] and Brogi [36], and our own experience.

A total of 165 lesions from 103 patients were included (Table 2). Pure lesions were defined as either columnar

Table 2 Overview of breast lesions studied for chromosome 16 changes

\begin{tabular}{llll}
\hline Samples & Type of lesion & $\begin{array}{l}\text { Lesions } \\
\text { (number) }\end{array}$ & $\begin{array}{l}\text { Mean age (year) } \\
\text { [range] }\end{array}$ \\
\hline All Lesions & BDA & 10 & $57.5[45-75]$ \\
& UDH & 13 & $56.3[34-76]$ \\
& CCL without & 12 & $57.8[48-72]$ \\
atypia & & \\
CCL with atypia & 11 & $50.3[41-67]$ \\
ADH & 19 & $52.8[37-84]$ \\
DCIS grade 1 & 14 & $51.9[37-82]$ \\
DCIS grade 2 & 11 & $54.0[32-68]$ \\
DCIS grade 3 & 10 & $58.0[34-80]$ \\
LN & 11 & $56.1[43-71]$ \\
IDC grade 1 & 12 & $58.8[45-73]$ \\
Tubular & 11 & $54.2[36-71]$ \\
carcinoma & & \\
IDC grade 2 & 11 & $54.6[34-74]$ \\
IDC grade 3 & 10 & $51.4[32-65]$ \\
ILC & 10 & $59.5[60-72]$ \\
BDA & 2 & $48.0[47-49]$ \\
Pure lesions & 5 & $53.6[34-76]$ \\
CCL without & 4 & $54.3[48-69]$ \\
atypia & & $48.6[44-51]$ \\
CCL with atypia & 5 & $53.3[39-84]$ \\
ADH & 11 & 5.96 \\
\hline
\end{tabular}

$\mathrm{ADH}$, atypical ductal hyperplasia; BDA, blunt duct adenosis; CCL, columnar cell lesion; DCIS, ductal carcinoma in situ; IDC, invasive ductal carcinoma; ILC, invasive lobular carcinoma; LN, lobular neoplasia; UDH, usual ductal hyperplasia; Pure lesions, lesions not associated with ductal carcinoma in situ or invasive carcinoma in the same breast. cell lesions, columnar cell-like lesions (usual ductal hyperplasia and blunt duct adenosis) or atypical ductal hyperplasia, not associated with ductal carcinoma in situ or invasive carcinoma in the same resection specimen or in the prior biopsy. Furthermore, 28 independent cases of normal breast formalin-fixed, paraffin-embedded tissue obtained from breast reductions specimen or autopsies were taken along as control and were tested to set reference values for copy number gains and losses.

Anonymous use of leftover tissue for research purposes is part of the standard treatment agreement with patients in our hospitals [37]. Pathological reports were used to retrieve information on age and coexistence of malignancy.

\section{DNA extraction and multiplex ligation-dependent probe amplification analysis}

For detailed technical description of DNA extraction, PCR analysis and multiplex ligation-dependent probe amplification (MLPA) analysis, see supplementary methods. The P451-A1 probemix (MRC-Holland) was designed to contain 6 probes on the $16 \mathrm{p}$ arm and 28 probes on the $16 \mathrm{q}$ arm. The target genes for the MLPA probes were chosen using the information provided in the Atlas of Genetics and Cytogenetics in Oncology and Haematology (http://atlasgeneticsoncology.org/). Only genes on chromosome 16 associated with cancer or possibly implicated in cancer were chosen to be included. Probe coverage on chromosome 16 was designed to have an even distribution of probes along the chromosomal arm with an average of 7.2 MB for the p-arm and 1.6 MB for the q-arm (highest distance 7.4 MB for the p-arm and 7.3 MB for the q-arm).

Also, 16 reference probes were included. See Fig. 1 and Supplementary Table 1 for detailed description of the probe locations.

All samples were tested in duplicate, except for three samples, because of a shortage of DNA. Cutoff values for gains and losses per probe were defined by the mean copy number ratios of 58 MLPA tests of 28 independent cases of normal breast tissue $\pm 2 \mathrm{SD}$. All values below the lowest cut-off value were defined as losses, and those above the highest cut-off value were defined as gains. The stated cutoff values are listed in Supplementary Table 2. Three probes (CDH1 Exon 1, FOXF1 Exon 2, SPG7 Exon 3) were excluded from further analysis due to high SDs $(>0.13)$ in normal breast tissue.

Whole-arm loss was defined, as described before, as copy number loss of $>75 \%$ of all tested genes of one chromosomal arm [38, 39]. Whole-arm gain was defined as gain of $>75 \%$ of all tested genes of one chromosomal arm. 


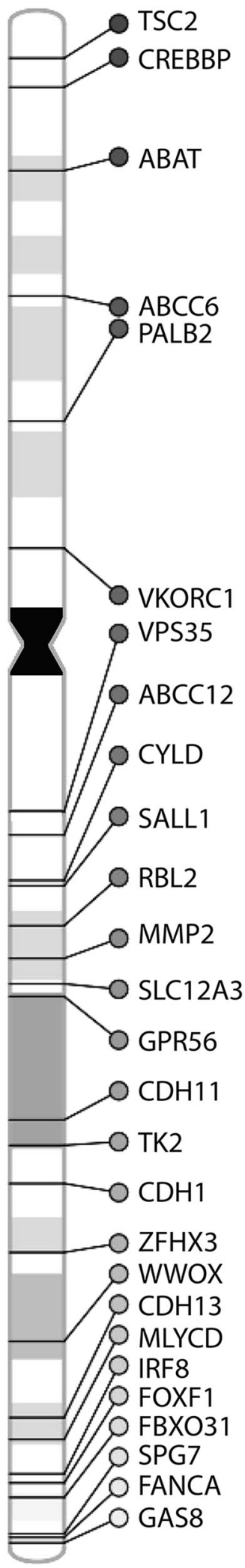

Fig. 1 Distribution of multiplex ligation-dependent probe amplification probes across chromosome 16. Legend: this figure was generated with the help of http://visualization.ritchielab.psu.edu/phenograms/ plot\#

\section{Statistical analysis}

Statistical calculations were performed using IBM SPSS for Windows version 20.0.

Mann-Whitney test was used to compare copy number ratios of each individual gene between different lesions. Unsupervised hierarchical clustering was performed using the statistical programme $\mathrm{R}$ (http://www.r-project.org), version 3.0.1, packages: gplots, pvclust and snow. We used Euclidean distance and Spearman's correlation together with Ward's clustering method.

\section{Results}

\section{Overall results}

The overall results are summarized in Table 3 . The most commonly lost probes differed per lesion and no smallest region of overlap was found for the low-nuclear-grade breast neoplasia family.

\section{Usual ductal hyperplasia}

In usual ductal hyperplasia lesions, the average percentage of copy number changes was $18 \%$. Losses on $16 \mathrm{q}$ were found in 11/13 lesions (85\%), with a maximum of 6 probes (Fig. 2). Nine lesions showed both gains and losses. Losses were only found in small clusters (with a maximum of three uninterrupted MLPA probe lost), separated by probes without copy number changes or single probes with gains.

Gains on $16 p$ were found in $7 / 13$ lesions $(54 \%)$. There were no whole-arm changes.

\section{Blunt duct adenosis}

In blunt duct adenosis lesions, the average percentage of copy number changes was $19 \%$. Losses on 16q were found in $10 / 10$ lesions $(100 \%)$, with a maximum of 8 probes per lesion (Fig. 2). Six lesions showed both gains and losses. The losses were only found in small clusters (with a maximum of three probes), separated by probes without copy number changes or single probes with gains.

Gains on $16 p$ were found in $6 / 10$ lesions $(60 \%)$. There were no whole-arm changes.

\section{Columnar cell lesions without atypia}

In columnar cell lesions without atypia the average percentage of copy number changes was $27 \%$. Losses on $16 \mathrm{q}$ were found in 12/12 lesions (100\%) (Fig. 3). CDH1 exon 11 was most commonly lost $(7 / 12=58 \%)$. Two out of 12 
Table 3 Overview results

\begin{tabular}{|c|c|c|c|c|c|c|c|c|c|c|c|c|c|c|c|}
\hline Lesion $(n)$ & $\begin{array}{l}\text { Aver } \\
\text { copy } \\
\text { numb } \\
\text { chans } \\
\text { chron } \\
\text { some }\end{array}$ & & $\begin{array}{l}16 \mathrm{q} \text { los } \\
(n)\end{array}$ & & $\begin{array}{l}\text { Comb } \\
\text { tion o } \\
\text { gains } \\
\text { losses } \\
16 \mathrm{q}(n\end{array}$ & & $\begin{array}{l}\text { Whole } \\
\text { arm } 1 \\
\text { loss }(r\end{array}$ & & $\begin{array}{l}\text { Gains } \\
16 \mathrm{p}(r\end{array}$ & & $\begin{array}{l}\text { Whol } \\
\text { arm } \\
\text { gain }\end{array}$ & & $\begin{array}{l}\text { Probe(s) most } \\
\text { commonly lost }\end{array}$ & $\begin{array}{l}\text { Frequ } \\
(n)\end{array}$ & \\
\hline $\mathrm{UDH}$ & (13) & $18 \%$ & $85 \%$ & (11) & $69 \%$ & (9) & $0 \%$ & (0) & $54 \%$ & (7) & $0 \%$ & (0) & MLYCD exon 2 & $38 \%$ & (5) \\
\hline BDA & (10) & $19 \%$ & $100 \%$ & (10) & $60 \%$ & (6) & $0 \%$ & (0) & $80 \%$ & (8) & $0 \%$ & (0) & SPG7 & $50 \%$ & (5) \\
\hline $\mathrm{CCL}-$ & (12) & $27 \%$ & $100 \%$ & (12) & $50 \%$ & (6) & $17 \%$ & (2) & $67 \%$ & (8) & $0 \%$ & (0) & CDH1 exon 11 & $58 \%$ & (7) \\
\hline $\mathrm{CCL}+$ & (11) & $40 \%$ & $100 \%$ & (11) & $36 \%$ & (4) & $27 \%$ & (3) & $55 \%$ & (6) & $9 \%$ & (1) & SLC12A3 & $91 \%$ & (10) \\
\hline $\mathrm{ADH}$ & (19) & $44 \%$ & $95 \%$ & (18) & $26 \%$ & (5) & $47 \%$ & (9) & $58 \%$ & (11) & $0 \%$ & (0) & $\begin{array}{l}\text { CDH11 exon } 3 \\
\text { CDH1 exon } 11\end{array}$ & $74 \%$ & (14) \\
\hline DCIS1 & (14) & $56 \%$ & $86 \%$ & (12) & $7 \%$ & (1) & $57 \%$ & (8) & $64 \%$ & (9) & $7 \%$ & (1) & $\begin{array}{l}\text { CDH1 exon } 11 \\
\text { MLYCD exon } 2 \\
\text { FBXO31 }\end{array}$ & $79 \%$ & (11) \\
\hline DCIS2 & (11) & $47 \%$ & $73 \%$ & (8) & $27 \%$ & (3) & $27 \%$ & (3) & $82 \%$ & (9) & $9 \%$ & (1) & CDH1 exon 11 & $73 \%$ & (8) \\
\hline DCIS3 & (10) & $49 \%$ & $90 \%$ & (9) & $60 \%$ & (6) & $10 \%$ & (1) & $80 \%$ & (8) & $0 \%$ & (0) & FANCA exon 20 & $80 \%$ & (8) \\
\hline TubCa & (11) & $64 \%$ & $91 \%$ & (10) & $9 \%$ & (1) & $55 \%$ & (6) & $73 \%$ & (8) & $27 \%$ & (3) & $\begin{array}{l}\text { CYLD } \\
\text { MMP2 } \\
\text { CDH1 } 1 \text { exon } 3 \\
\text { FANCA exon } 20\end{array}$ & $91 \%$ & (10) \\
\hline IDC1 & (12) & $65 \%$ & $92 \%$ & (11) & $17 \%$ & (2) & $42 \%$ & (5) & $92 \%$ & (11) & $25 \%$ & (3) & CYLD & $83 \%$ & (10) \\
\hline IDC2 & (11) & $58 \%$ & $91 \%$ & (10) & $27 \%$ & (3) & $36 \%$ & (4) & $82 \%$ & (9) & $27 \%$ & (3) & $\begin{array}{l}\text { CYLD } \\
\text { WWOX exon } 10 \\
\text { FANCA exon } 20\end{array}$ & $73 \%$ & (8) \\
\hline IDC3 & (10) & $63 \%$ & $80 \%$ & (8) & $50 \%$ & (5) & $30 \%$ & (3) & $90 \%$ & (9) & $20 \%$ & (2) & $\begin{array}{l}\text { CDH11 exon } 8 \& 3 \\
\text { ZFHX3 } \\
\text { MLYCD exon } 3\end{array}$ & $70 \%$ & (7) \\
\hline $\mathrm{LN}$ & (11) & $53 \%$ & $91 \%$ & (10) & $9 \%$ & (1) & $45 \%$ & (5) & $55 \%$ & (6) & $0 \%$ & (0) & SLC12A3 & $82 \%$ & (9) \\
\hline ILC & (10) & $73 \%$ & $100 \%$ & (10) & $0 \%$ & $(0)$ & $80 \%$ & (8) & $60 \%$ & (6) & $10 \%$ & (1) & $\begin{array}{l}\text { MMP2 } \\
\text { SLC12A3 } \\
\text { CDH1 exons } 11 \& 14 \\
\text { WWOX exon } 10 \\
\text { MLYCD exon } 2 \\
\text { FANCA exon } 20\end{array}$ & $90 \%$ & (9) \\
\hline
\end{tabular}

$\mathrm{ADH}$, atypical ductal hyperplasia; BDA, blunt duct adenosis; $\mathrm{CCL}-$, columnar cell lesion without atypia; $\mathrm{CCL}+$, columnar cell lesion with atypia; DCIS, ductal carcinoma in situ; IDC, invasive ductal carcinoma; ILC, invasive lobular carcinoma; LN, lobular neoplasia; TubCa, tubular carcinoma; UDH, usual ductal hyperplasia.

lesions (17\%) fulfilled the criteria for whole-arm loss of 16q. Six lesions showed both gains and losses.

Gains on 16p were found in 8 out of 12 lesions (67\%) but none of these lesions fulfilled the criteria for whole-arm gain of $16 \mathrm{p}$.

\section{Columnar cell lesions with atypia}

In columnar cell lesions with atypia, the average percentage of copy number changes was $40 \%$. Losses on $16 \mathrm{q}$ were found in 11/11 lesions (100\%) (Fig. 3). SLC12A3 was most commonly lost $(10 / 11=91 \%)$. Three out of 11 lesions (27\%) fulfilled the criteria for whole-arm loss of 16q. In four lesions there were both gains and losses.
Gains on 16p were found in 6/11 lesions (55\%) and one of these lesions fulfilled the criteria for whole-arm gain of $16 p$.

\section{Atypical ductal hyperplasia}

In atypical ductal hyperplasia lesions, the average percentage of copy number changes was $44 \%$. Losses on $16 \mathrm{q}$ were found in 18/19 lesions (95\%) (Fig. 3). CDH11 exon 3 and $C D H 1$ exon 11 were most commonly lost $(14 / 19=74 \%)$. Nine out of 19 lesions $(47 \%)$ fulfilled the criteria for whole-arm loss of 16q. In five lesions, there were both gains and losses. In one case, gain of the first two tested genes on $16 \mathrm{q}$ adjacent to the centromere 

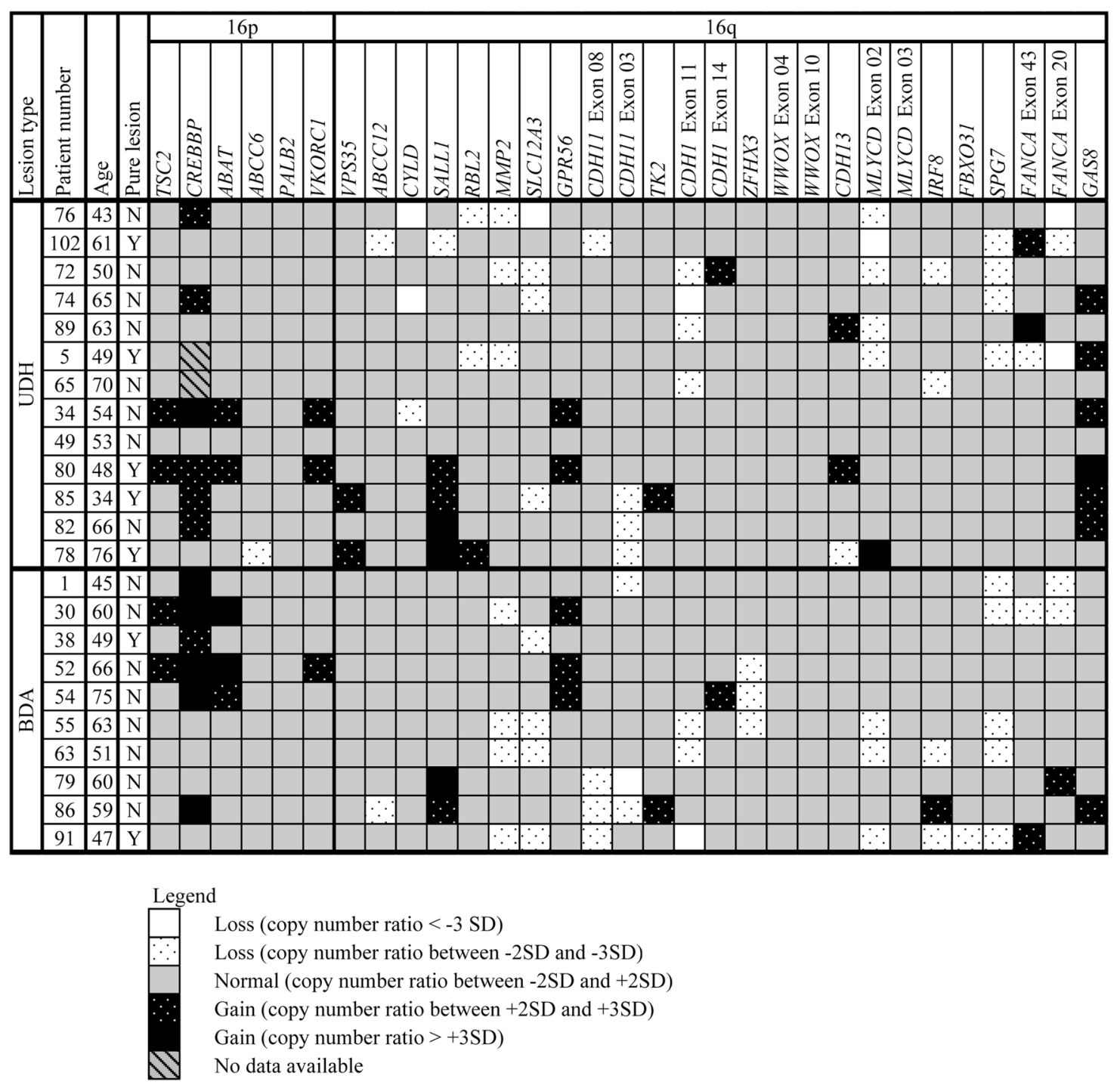

Fig. 2 Gains and losses by multiplex ligation-dependent probe amplification in genes on chromosome 16 in usual ductal hyperplasia and blunt duct adenosis lesions. BDA, blunt duct adenosis; N, no; UDH, usual ductal hyperplasia; Y, yes

was associated with losses of other investigated genes on $16 \mathrm{q}$.

Gains on 16p were found in 11/19 lesions (58\%) but none of these lesions fulfilled the criteria for whole-arm gain of $16 \mathrm{p}$.

\section{Ductal carcinoma in situ grade 1}

In ductal carcinoma in situ grade 1 , the average percentage of copy number changes was $56 \%$. Losses on $16 \mathrm{q}$ were found in 12/14 lesions (86\%) (Fig. 4). $C D H 1$ exon 11, MLYCD exon 2 and FBXO31 were most commonly lost $(11 / 14=79 \%)$. Eight out of 14 lesions $(57 \%)$ fulfilled the criteria for whole-arm loss of 16q. In only one lesion there were gains as well as losses. Gains on 16p were found in 9/14 lesions (64\%) and 1 of these lesions fulfilled the criteria for whole-arm gain of 16p.

\section{Ductal carcinoma in situ grade 2}

In ductal carcinoma in situ grade 2, the average percentage of copy number changes was $47 \%$. Losses on $16 q$ were found in 8/11 lesions (73\%) (Fig. 4). $\mathrm{CDH1}$ exon 11 was most commonly lost $(8 / 11=73 \%)$. Three out of 11 lesions (27\%) fulfilled the criteria for whole-arm loss of $16 \mathrm{q}$. In three lesions there were both gains and losses.

Gains on $16 p$ were found in $9 / 11$ lesions $(82 \%)$ and 1 of these lesions fulfilled the criteria for whole-arm gain of $16 \mathrm{p}$. 

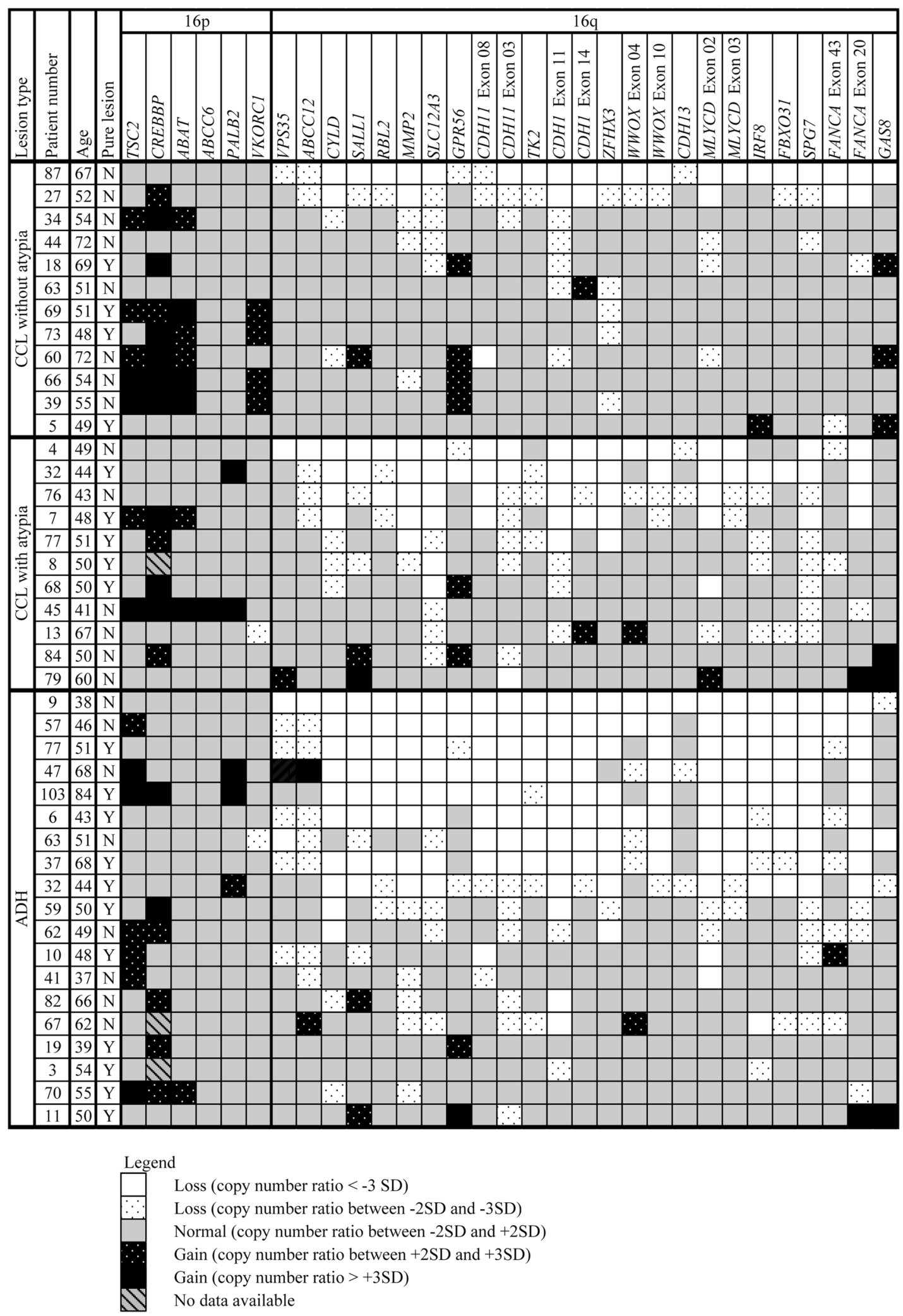

Fig. 3 Gains and losses by multiplex ligation-dependent probe amplification in genes on chromosome 16 in columnar cell lesions without atypia, columnar cell lesions with atypia and atypical ductal hyperplasia. ADH, atypical ductal hyperplasia; CCL, columnar cell lesion; N, no; Y, yes 

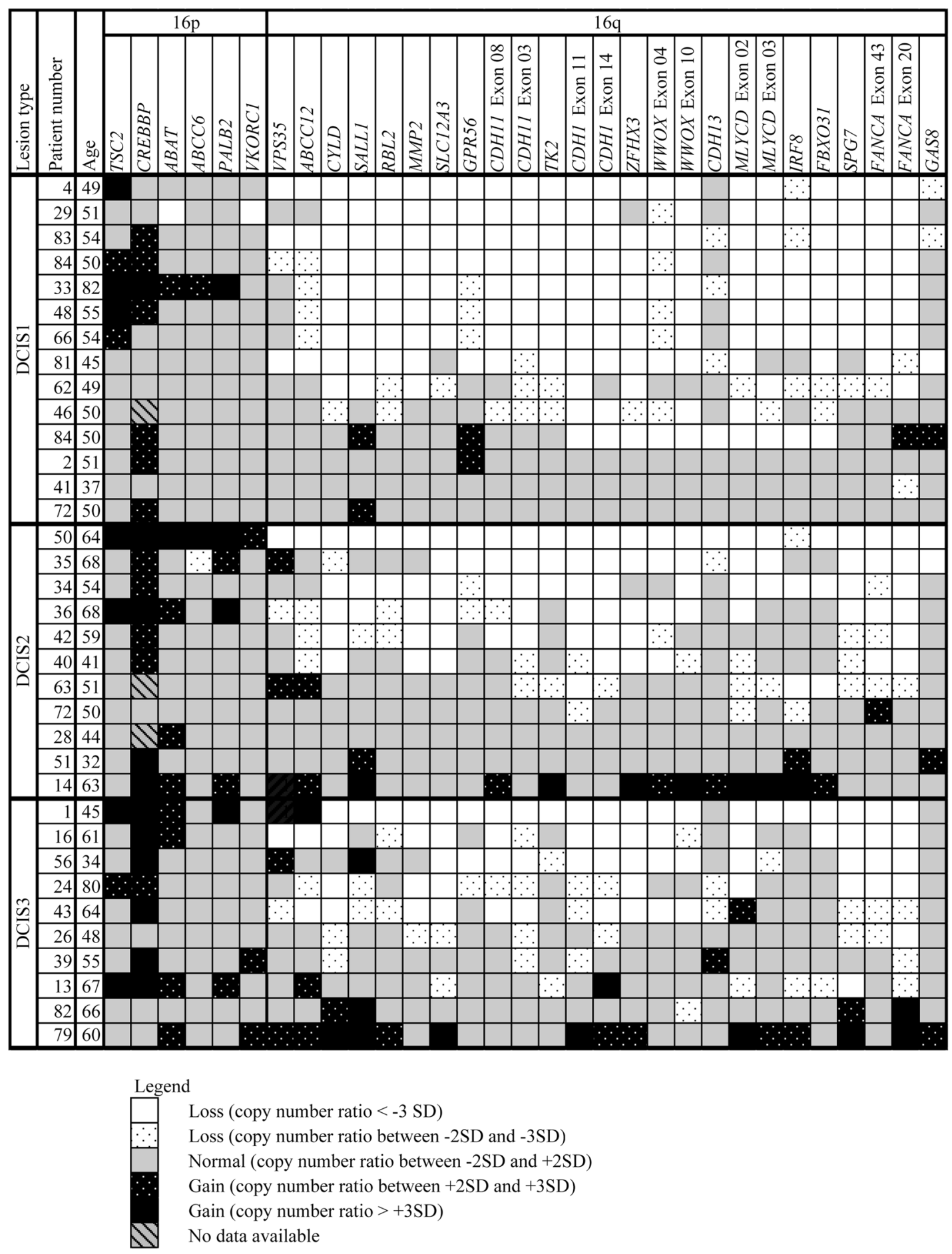

Fig. 4 Gains and losses by multiplex ligation-dependent probe amplification in genes on chromosome 16 in ductal carcinoma in situ lesions. DCIS, ductal carcinoma in situ

\section{Ductal carcinoma in situ grade 3}

In ductal carcinoma in situ grade 3 , the average percentage of copy number changes was $49 \%$. Losses on $16 \mathrm{q}$ were found in 9/10 lesions (90\%) (Fig. 4). FANCA exon 20 was most commonly lost $(8 / 10=80 \%)$. One out of 10 lesions $(10 \%)$ fulfilled the criteria for whole-arm loss of 16q. In six lesions there were both gains and losses. In one case gain of the first two tested genes on $16 \mathrm{q}$ adjacent to the centromere was associated with losses of other investigated genes on 16q. 

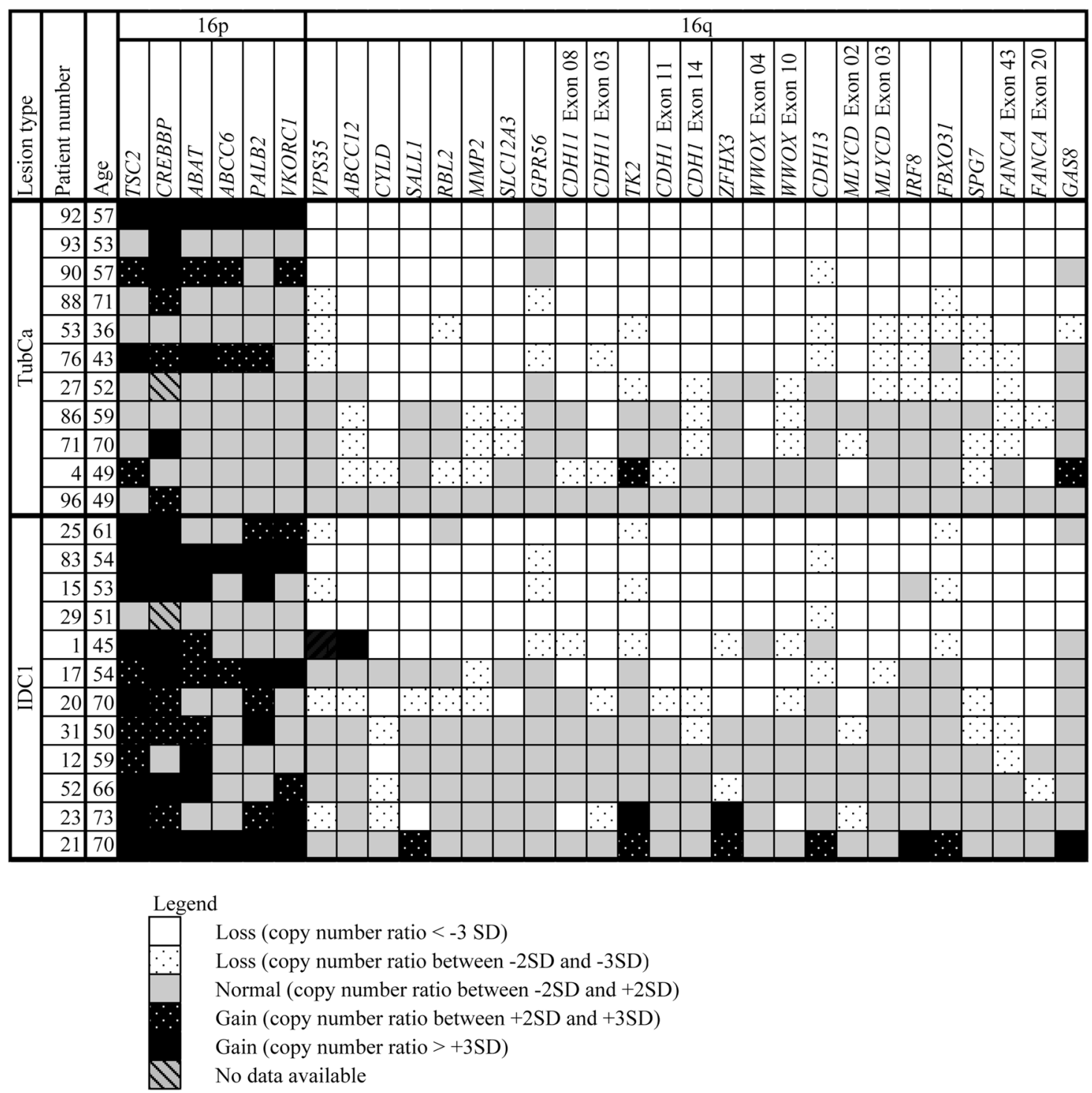

Fig. 5 Gains and losses by multiplex ligation-dependent probe amplification in genes on chromosome 16 in tubular carcinomas and grade 1 invasive ductal carcinomas. IDC, invasive ductal carcinoma; TubCa, tubular carcinoma

Gains on $16 \mathrm{p}$ were found in $8 / 10$ lesions $(80 \%)$ but none of these lesions fulfilled the criteria for whole-arm gain of $16 \mathrm{p}$.

\section{Invasive ductal carcinoma grade 1 and tubular carcinoma}

Two types of low-grade invasive ductal carcinomas were included: tubular carcinomas and invasive ductal carcinoma grade 1 . In invasive ductal carcinoma grade 1 , the average percentage of copy number changes was $65 \%$ (Fig. 5). Losses on $16 \mathrm{q}$ were found in $11 / 12$ lesions $(92 \%)$. CYLD was most commonly lost $(10 / 12=83 \%)$. Five out of 12 lesions $(42 \%)$ fulfilled the criteria for whole-arm loss of 16q. In two lesions there were both gains and losses. In one case gain of the first two tested genes on 16q adjacent to the centromere was associated with losses of other investigated genes on $16 \mathrm{q}$.

Gains on 16p were found in 11/12 lesions (92\%) and three of these lesions fulfilled the criteria for whole-arm gain of $16 \mathrm{p}$.

In tubular carcinomas, the average percentage of copy number changes was $64 \%$ (Fig. 5). Losses on $16 \mathrm{q}$ were found in 10 lesions $(10 / 11=91 \%)$. CYLD, $M M P 2, C D H 11$ exon 3 and FANCA exon 20 were most commonly lost (10/ $11=91 \%)$. Six out of 11 lesions $(55 \%)$ fulfilled the criteria for whole-arm loss of 16q. In one lesion there were both gains and losses.

Gains on 16p were found in 8/11 lesions (73\%) and 3 of these lesions fulfilled the criteria for whole-arm gain of $16 \mathrm{p}$. 

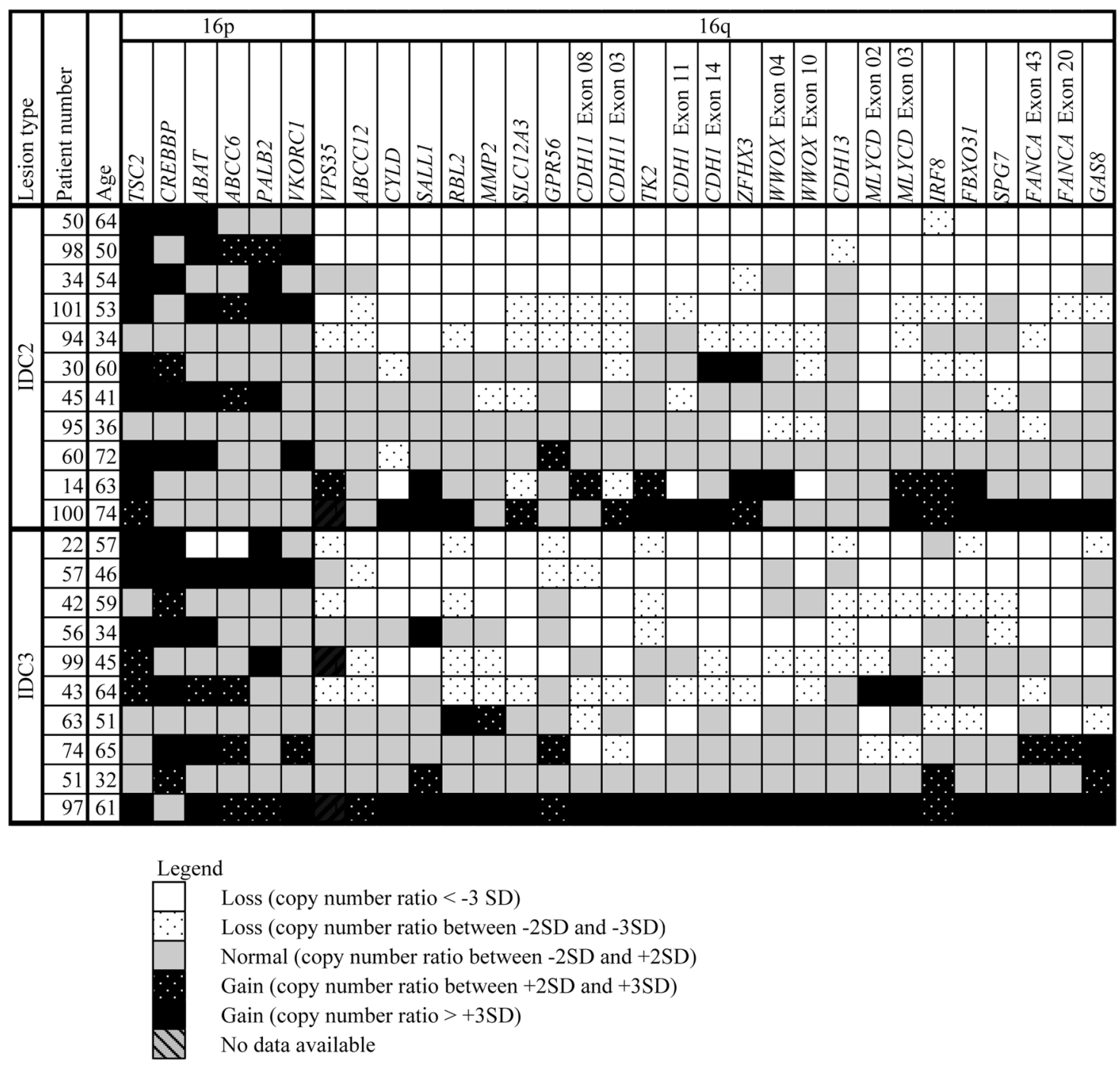

Fig. 6 Gains and losses by multiplex ligation-dependent probe amplification in genes on chromosome 16 in invasive ductal carcinomas grade 2 or 3. IDC, invasive ductal carcinoma

\section{Invasive ductal carcinoma grade 2}

In invasive ductal carcinoma grade 2 , the average percentage of copy number changes was $58 \%$ (Fig. 6). Losses on $16 \mathrm{q}$ were found in $10 / 11$ lesions $(91 \%)$. CYLD, WWOX exon 10 and FANCA exon 20 were most commonly lost (8/ $11=73 \%)$. Four out of 11 lesions $(36 \%)$ fulfilled the criteria for whole-arm loss of 16q. In three lesions there were both gains and losses.

Gains on 16p were found in 9/11 lesions (82\%) and 3 of these lesions fulfilled the criteria for whole-arm gain of $16 p$.

\section{Invasive ductal carcinoma grade 3}

In invasive ductal carcinoma grade 3 , the average percentage of copy number changes was $63 \%$ (Fig. 6). Losses on
$16 \mathrm{q}$ were found in $8 / 10$ lesions (80\%). CDH11 exon 8 and 3, ZFHX3 and MLYCD exon 3 were most commonly lost. Three out of 10 lesions (30\%) fulfilled the criteria for whole-arm loss of 16q. In five lesions there were both gains and losses. In one lesion there was polysomy of whole chromosome 16. Gains on 16p were found in 9/10 lesions (90\%) and 2 of these lesions fulfilled the criteria for wholearm gain of $16 \mathrm{p}$.

\section{Lobular neoplasia and invasive lobular carcinoma}

In lobular neoplasia, the average percentage of copy number changes was 53\% (Fig. 7). Losses on 16q were found in 10/ 11 lesions (91\%). SLC12A3 was most commonly lost $(9 / 11$ $=82 \%$ ), closely followed by $M M P 2, C D H 11$ exon 3, $C D H 1$ exon 11, MYCD exon 2, SPG7 and FANCA exons 43 

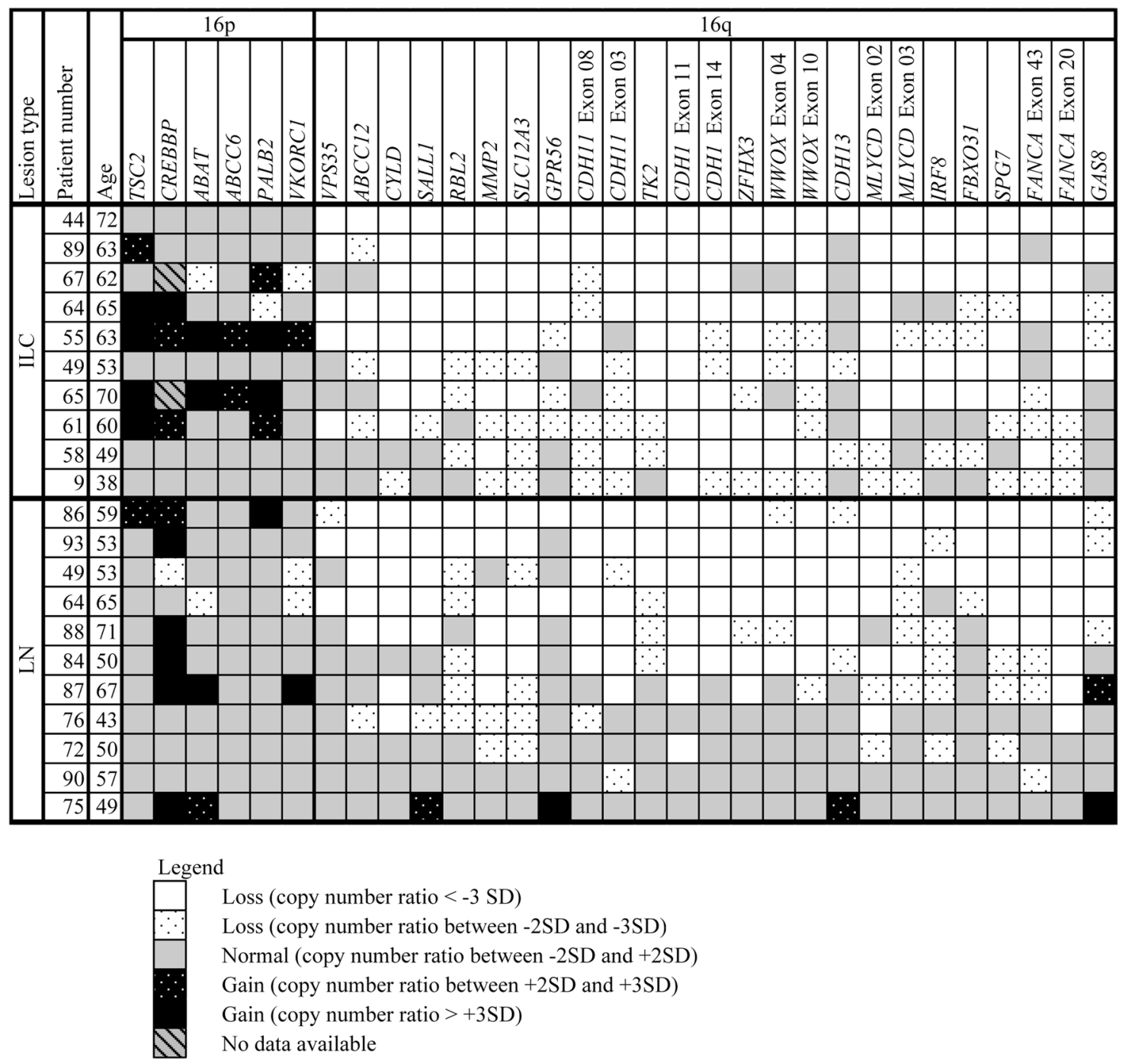

Fig. 7 Gains and losses by multiplex ligation-dependent probe amplification in genes on chromosome 16 in invasive lobular carcinomas and lobular neoplasia. ILC, invasive lobular carcinoma; LN, lobular neoplasia

and $20(8 / 11=73 \%)$. Five out of 11 lesions $(45 \%)$ fulfilled the criteria for whole-arm loss of 16q. In one lesion there were both gains and losses.

Gains on $16 \mathrm{p}$ were found in $6 / 11$ lesions $(55 \%)$ but none of these lesions fulfilled the criteria for whole-arm gain of $16 \mathrm{p}$.

In invasive lobular carcinoma, the average percentage of copy number changes was $73 \%$ (Fig. 7). Losses on $16 \mathrm{q}$ were found in 10/10 lesions (100\%). MMP2, SLC12A3, $C D H 1$ exons 11 and $14, W W O X$ exon $10, M L Y C D$ exon 2 and FANCA exon 20 were most commonly lost. Eight out of 10 lesions $(80 \%)$ fulfilled the criteria for whole-arm loss of 16q. There were no lesions with both gains and losses on $16 \mathrm{q}$.

Gains on $16 p$ were found in $6 / 10$ lesions $(60 \%)$ and 1 of these lesions fulfilled the criteria for whole-arm gain of $16 \mathrm{p}$.

\section{Comparison of $16 q$ losses between lesion categories}

The percentages of $16 \mathrm{q}$ losses over the spectrum usual ductal hyperplasia, blunt duct adenosis, columnar cell lesion without atypia, columnar cell lesion with atypia, atypical ductal hyperplasia and ductal carcinoma in situ grade 1 gradually increased as shown in Fig. 8a. In ductal carcinoma in situ grade 1 , invasive ductal carcinoma grade 1 , tubular carcinoma and lobular neoplasia the percentages of losses were similar. Invasive lobular carcinoma had the highest percentage of loss on 16q.

Although whole-arm losses were not found in usual ductal hyperplasia and blunt duct adenosis lesions, there was an increase in whole-arm losses of 16q from columnar cell lesion without atypia, to columnar cell lesion with atypia and atypical ductal hyperplasia (Fig. 8b). In atypical ductal hyperplasia, ductal carcinoma in situ grade 1, 

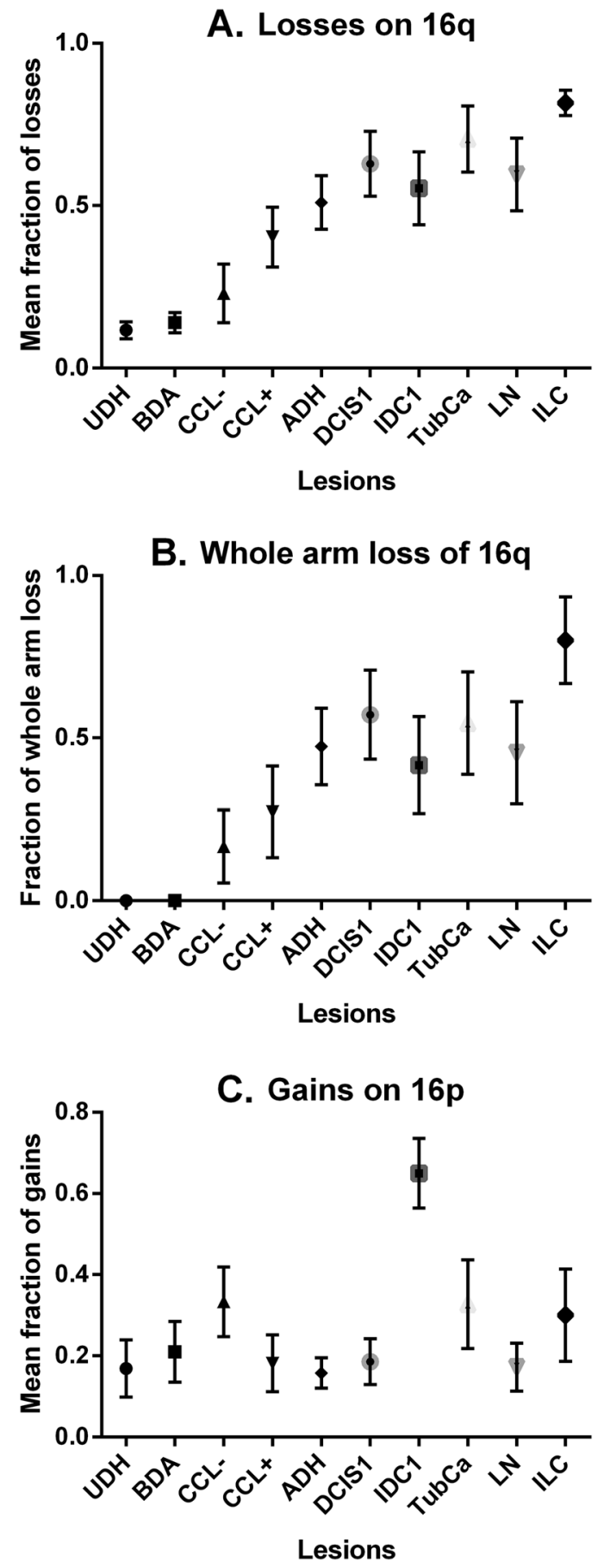

Fig. 8 Trends in copy number changes in low-grade breast carcinogenetic spectrum. a Increasing frequency of $16 \mathrm{q}$ losses over the lowgrade breast carcinogenetic spectrum. b Increasing frequency of $16 q$ whole-arm loss over the low-grade breast carcinogenetic spectrum. c No trend of increasing 16p gains over the low-grade breast carcinogenetic spectrum. ADH, atypical ductal hyperplasia; BDA, blunt duct adenosis; $\mathrm{CCL}-$, columnar cell lesion without atypia; $\mathrm{CCL}+$, columnar cell lesion with atypia; DCIS, ductal carcinoma in situ; IDC, invasive ductal carcinoma; ILC, invasive lobular carcinoma; LN, lobular neoplasia; TubCa, tubular carcinoma; UDH, usual ductal hyperplasia invasive ductal carcinoma grade 1 and tubular carcinoma the percentages of $16 q$ whole-arm losses were similar, ranging from $42 \%$ to $57 \%$. The highest percentage of whole-arm losses was found in invasive lobular carcinoma $(80 \%)$.

\section{Lesions not fulfilling whole-arm loss}

In benign lesions (usual ductal hyperplasia and blunt duct adenosis), losses were only found in small clusters (with a maximum of three uninterrupted MLPA probe lost), separated by probes without copy number changes or single probes with gains. A maximum losses of eight probes per lesion (in blunt duct adenosis) was found. In 34 other lesions, the number of losses was between 9 and 18, thereby having more losses compared with the benign lesions, but not fulfilling the criteria for whole-arm loss. These cases included three columnar cell lesions with atypia, three atypical ductal hyperplasia lesions, three ductal carcinoma in situ grade 1 lesions, four tubular carcinomas, two invasive ductal carcinomas grade 1, three lobular neoplasias and two invasive lobular carcinomas. In almost all of these cases, losses were spread across the whole-arm, interspersed with small areas without copy number changes. In one ductal carcinoma in situ grade 1 , there was loss of a contiguous region between $C D H 1$ exon 11 and FBXO31, suggestive for partial arm loss.

\section{Breakpoints on $16 q$}

In $65 \%$ of cases with whole-arm losses, the breakpoint seemed to be around the centromere (between VKORCl and VPS35), and in $18 \%$ between $A B C C 12$ and CYLD. In three cases (atypical ductal hyperplasia, invasive ductal carcinoma grade 1 and ductal carcinoma in situ grade 3 ) with this breakpoint, there was gain of VPS35 and ABCC12.

\section{Comparison of $16 \mathrm{p}$ gains between lesion categories}

In contrast to $16 \mathrm{q}$ losses, there was no increase in percentage of $16 p$ gains or $16 p$ whole-arm gains in the low-grade carcinogenesis sequence from columnar cell lesions to atypical ductal hyperplasia, low-grade ductal carcinoma in situ and low-grade invasive carcinoma (Fig. 8c). In total, there were 16 cases with whole-arm gain of $16 p$, of which 11 were associated with whole-arm loss of $16 \mathrm{q}(69 \%)$.

\section{Pure lesions and lesions associated with neoplasia}

There was a nonsignificant difference between the mean copy number ratios of all pure and neoplasia associated lesions (measured in the whole group of usual ductal 
hyperplasia, blunt duct adenosis, columnar cell lesion without atypia, columnar cell lesion with atypia and atypical ductal hyperplasia). Also, the mean copy number ratios of columnar cell lesions with atypia and atypical ductal hyperplasia lesions were similar between the pure group and the neoplasia associated group. Clustering with Euclidian distance and Spearman's correlation did not yield clusters of pure and malignancy-associated lesions.

\section{Comparison of different lesions within the same patient}

We tested eight columnar cell lesions without atypia, associated with (pre)malignant lesions in the same breast (Fig. 9). In two cases (patient 27 and patient 87), the columnar cell lesion without atypia revealed whole-arm loss. In these cases the copy number pattern was similar in the (pre)malignant lesions from the same breast (tubular carcinoma and lobular neoplasia, respectively), although both just did not fulfil the criteria for whole-arm loss. In two other cases (patients 34 and 44) there were fewer losses in the columnar cell lesion, but the losses in the columnar cell lesion were also found in the related (pre)malignant lesions (ductal carcinoma in situ grade 2, invasive ductal carcinoma grade 2 and invasive lobular carcinoma, respectively). In three cases (patients 39,63 and 54) the columnar cell lesion had a very low rate of copy number changes with no striking similarities between these changes and the copy number changes of the associated (pre)malignant lesions.

Further, copy number changes were compared between eight cases of columnar cell lesion with atypia associated with other (pre)malignant lesions in the same breast (Fig. 10). In all three atypical columnar cell lesion cases with whole-arm loss (patients 4, 32 and 76), there was also whole-arm loss in the associated (pre)malignant lesion (ductal carcinoma in situ grade 1, atypical ductal hyperplasia and tubular carcinoma, respectively). On the other hand, in patient 4 the tubular carcinoma did not show whole-arm loss and was probably not related to the associated columnar cell lesion and ductal carcinoma in situ
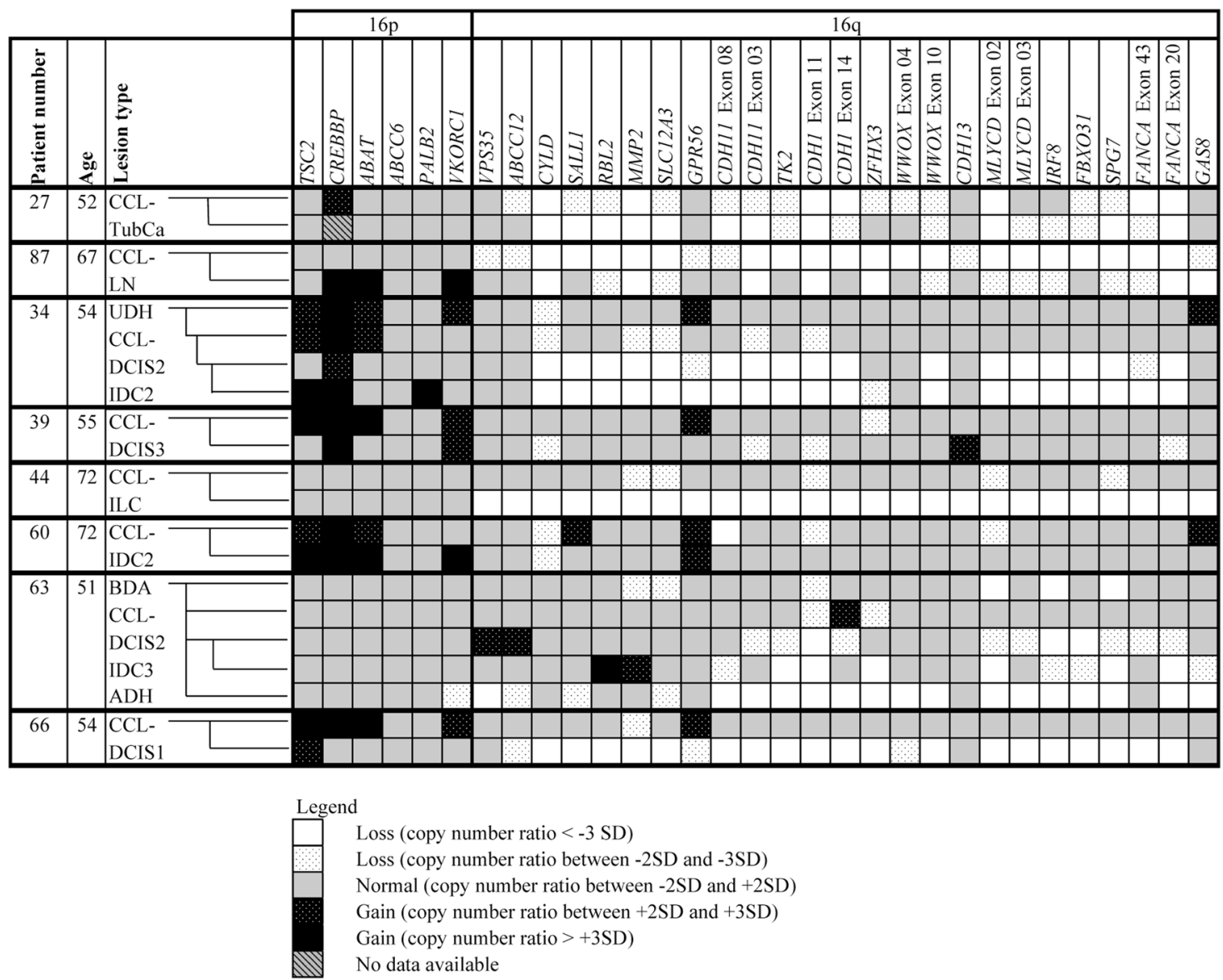

Fig. 9 Comparison of columnar cell lesions without atypia and concomitant (pre)neoplastic lesions within the same breast. Comparison of $16 \mathrm{p}$ and $16 \mathrm{q}$ copy number changes by multiplex ligation-dependent probe amplification in columnar cell lesions without atypia and concomitant (pre)neoplastic lesions within the same breast, showing many similarities. ADH, atypical ductal hyperplasia; BDA, blunt duct adenosis; CCL-, columnar cell lesion without atypia; DCIS, ductal carcinoma in situ; IDC, invasive ductal carcinoma; ILC, invasive lobular carcinoma; LN, lobular neoplasia; TubCa, tubular carcinoma; UDH, usual ductal hyperplasia 

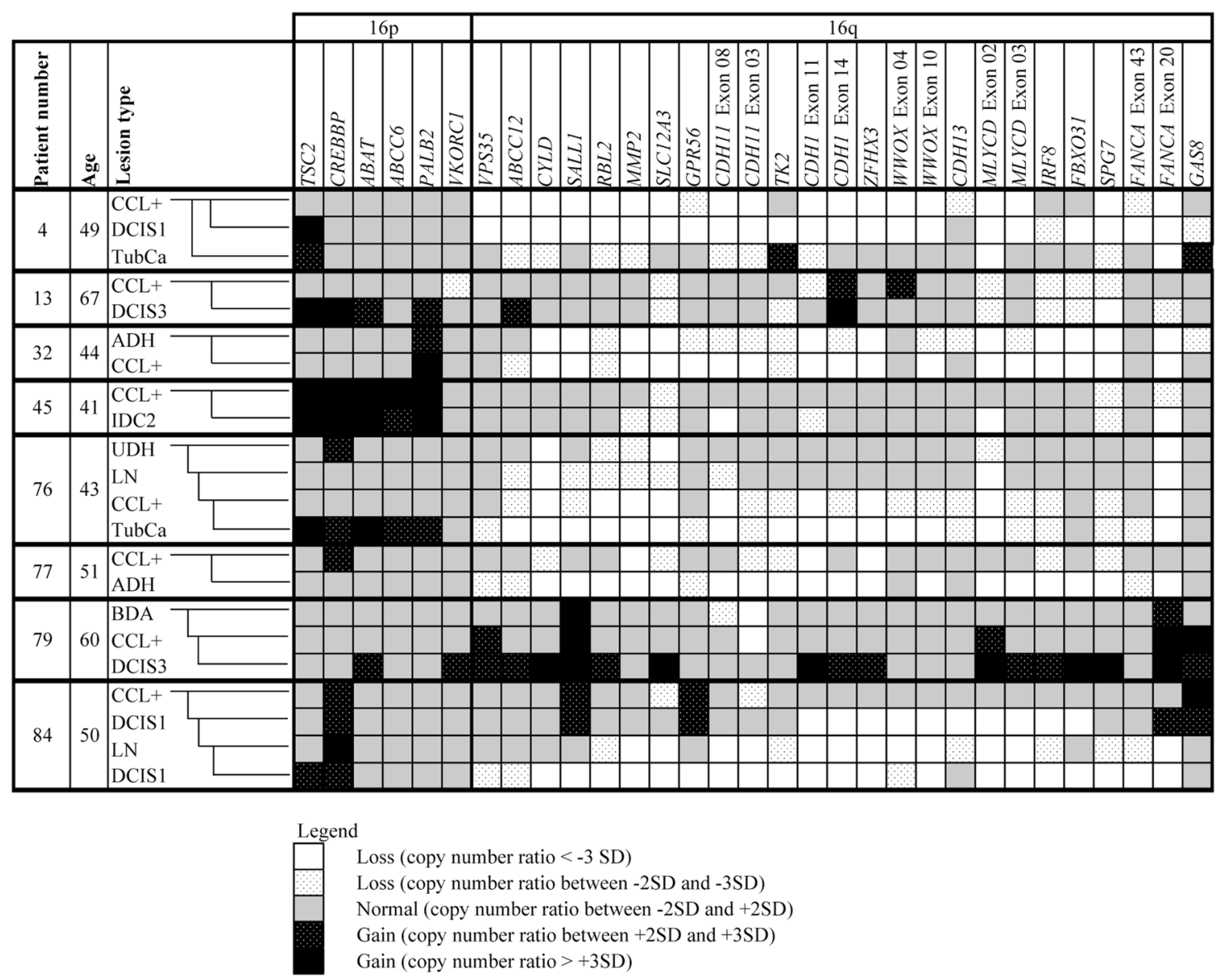

Fig. 10 Comparison of columnar cell lesions with atypia and concomitant (pre)neoplastic lesions within the same breast. Comparison of $16 p$ and 16q copy number changes by multiplex ligation-dependent probe amplification in columnar cell lesions with atypia and concomitant (pre)neoplastic lesions within the same breast, showing many

grade 1. In one other case (patient 77) there were fewer losses in the columnar cell lesion, but the losses corresponded to the associated atypical ductal hyperplasia. Patient 79 had a columnar cell lesion with a few gains on 16q. The associated ductal carcinoma in situ grade 3 had corresponding and additional gains. Patient 45 had a columnar cell lesion and invasive ductal carcinoma grade 2, both with whole-arm 16p gain. In two cases (patients 13 and 84 ), only some of the copy number changes present in the columnar cell lesion were also found back in concomitant (pre)malignant lesions.

Next, seven cases of atypical ductal hyperplasia with concomitant other (pre)malignant lesions in the same breast were analysed (Fig. 11). One out of three atypical ductal hyperplasia lesions with $16 \mathrm{q}$ whole-arm loss (patient 57) was associated with invasive ductal carcinoma grade 3 with 16q whole-arm loss. Patient 9 had atypical ductal hyperplasia with $16 \mathrm{q}$ whole-arm loss and invasive lobular carcinoma with extensive $16 \mathrm{q}$ loss but not fulfilling the criteria for whole-arm loss. Patient 63 had atypical ductal similarities. ADH, atypical ductal hyperplasia; BDA, blunt duct adenosis; CCL +, columnar cell lesion with atypia; DCIS, ductal carcinoma in situ; IDC, invasive ductal carcinoma; LN, lobular neoplasia; TubCa, tubular carcinoma; UDH, usual ductal hyperplasia

hyperplasia with whole-arm loss, but ductal carcinoma in situ grade 2 and invasive ductal carcinoma grade 3 with losses only at the distal part of 16q. Patient 62 had both atypical ductal hyperplasia and ductal carcinoma in situ grade 1. The atypical ductal hyperplasia revealed fewer losses on 16q but all losses were also found in the ductal carcinoma in situ lesion. In patient 67 the copy number changes (both gains and losses) of atypical ductal hyperplasia only partly corresponded to the copy number changes of the concomitant invasive lobular carcinoma. Lastly, there were no similarities between atypical ductal hyperplasia and ductal carcinoma in situ lesions (grade 1 and grade 3 ) in two patients (patients 41 and 82).

\section{Discussion}

It is now widely accepted that invasive breast cancer progresses from early, non-cancerous breast lesions in multiple, parallel pathways [4, 40], and columnar cell 

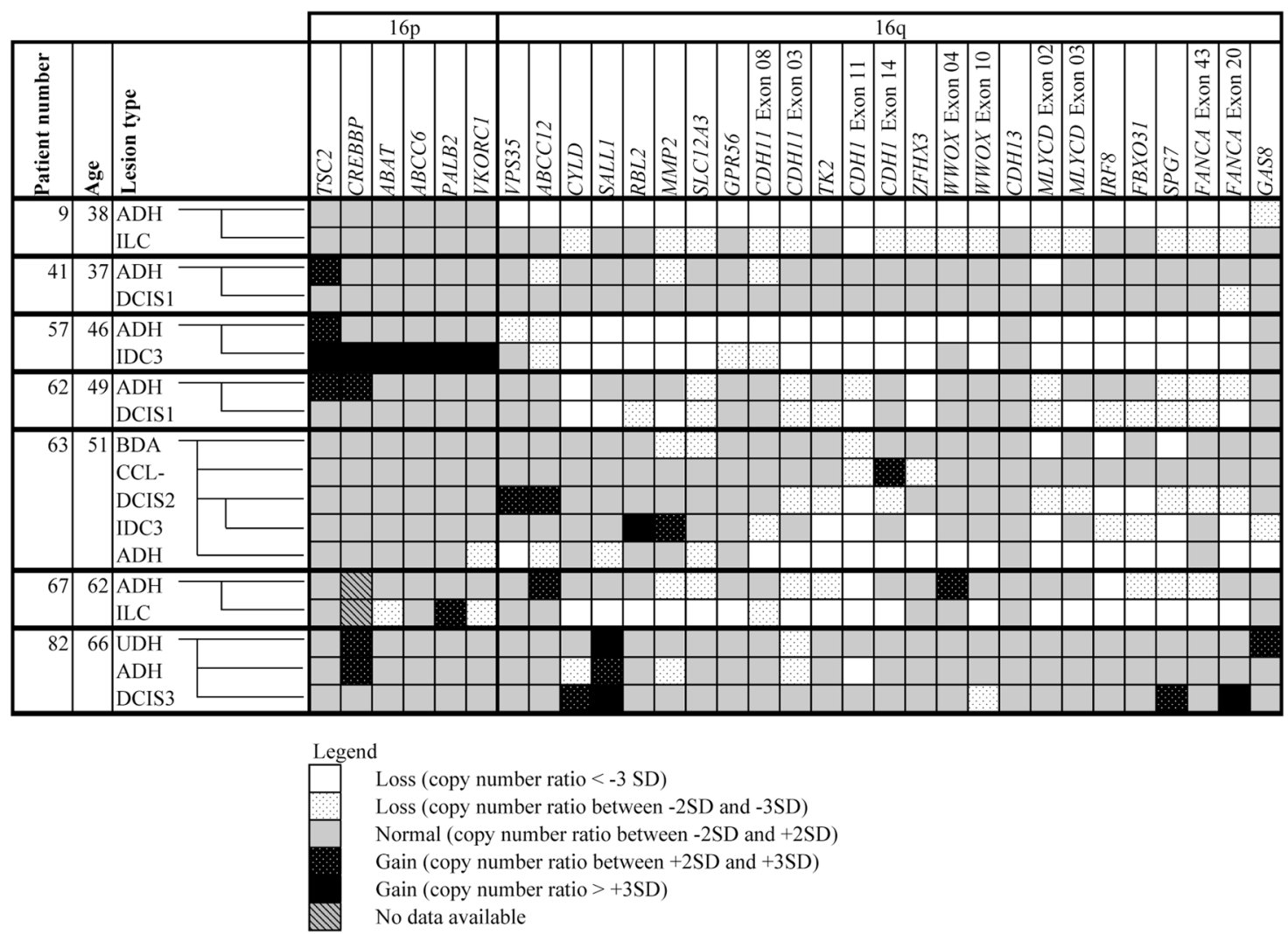

Fig. 11 Comparison of atypical ductal hyperplasia and concomitant (pre)neoplastic lesions within the same breast. Comparison of $16 p$ and $16 \mathrm{q}$ copy number changes by multiplex ligation-dependent probe amplification in atypical ductal hyperplasia and concomitant (pre) neoplastic lesions within the same breast, showing many similarities.

lesions seem to represent the earliest morphologically recognizable precursor lesion of the low nuclear grade breast neoplasia family.

This study investigated chromosome 16 copy number alterations in columnar cell lesions, atypical ductal hyperplasia and associated lesions of the breast by MLPA, circumventing whole-genome-amplification protocols, in order to minimize technical artefacts. The underlying aim was to support the precursor role of columnar cell lesions in lownuclear-grade breast carcinogenesis, and to clarify the role of columnar cell lesions without atypia, blunt duct adenosis and usual ductal hyperplasia in breast carcinogenesis.

MLPA is an easy and fast method to identify copy number changes of multiple genes, even in fragmented DNA, by a single PCR-based reaction [41]. The concordance between MLPA and other molecular techniques such as array-comparative genomic hybridization and fluorescent in situ hybridization has been confirmed in the past [42, 43]. Nevertheless, this study has its limitations and assumptions. One of the issues we faced during this study was the relatively low DNA content of the smaller lesions and lesions with prominent stroma, such as columnar cell
$\mathrm{ADH}$, atypical ductal hyperplasia; BDA, blunt duct adenosis; CCL-, columnar cell lesion without atypia; DCIS, ductal carcinoma in situ; IDC, invasive ductal carcinoma; ILC, invasive lobular carcinoma; UDH, usual ductal hyperplasia

lesion, lobular neoplasia and blunt duct adenosis. In these cases we could have missed gains and losses because of the admixture of normal DNA.

We defined whole-arm loss as $>75 \%$ loss of the residing genes/probes. This is a generally accepted cut-off value, which has been used previously in array-comparative genomic hybridization [39] and MLPA [38] experiments. The retained presence of some probes $(<25 \%)$ could be explained by the normalization process. Normalization was done in a probe-specific manner and the cut-off values for loss and gain were determined per probe, based on the MLPA ratio variation in normal breast tissue (see Supplementary Table 2). Together with the varying relative DNA content, this could also explain the subtle differences between related lesions.

The frequencies of $16 \mathrm{q}$ whole-arm losses detected with MLPA in invasive lobular carcinoma and invasive ductal carcinoma grade 1 were similar to previous arraycomparative genomic hybridization results $[12,44]$, corroborating our MLPA approach. None of our tested usual ductal hyperplasia and blunt duct adenosis lesions showed whole-arm losses of 16q. This confirms that, although some 
authors considered blunt duct adenosis to be a synonym of columnar cell lesion (without atypia) [45-47] or a growth pattern of columnar cell lesions [48], this lesion seems to be a separate entity and no precursor lesions of low-grade breast neoplasia. And this underlines the importance of morphologically discriminating blunt duct adenosis from columnar cell lesion.

Seventeen percent of the columnar cell lesions without atypia and $27 \%$ of columnar cell lesions with atypia showed whole-arm loss of chromosome 16q. In addition, three more columnar cell lesions with atypia had more losses compared with the benign columnar cell lesion-like lesions, but just did not fulfil the criteria for whole-arm losses. It is possible, given the small lesion size and abundance of surrounding stroma, that we missed whole-arm loss in these cases, caused by intermixture of normal DNA. Taking these lesions into account, it leads to a total of $54 \%$ of columnar cell lesions with atypia with significant losses on 16q. This result is in line with previously obtained results (40-70\% loss) by (array) comparative genomic hybridization (see Table 1) $[6,26]$.

These frequent whole-arm losses in columnar cell lesions with and without atypia, and the coexistence of columnar cell lesion with more advanced (pre)malignant lesions with similar losses, support a precursor role of columnar cell lesions in low-grade breast neoplasia. There were only sporadic cases in which the number of lost probes was lower in the more advanced lesion compared to the columnar cell lesion. For example, in case 87, the lower number of losses in the lobular neoplasia could be explained by the small size of the lesion and admixture of normal DNA. Although whole-arm loss could not be demonstrated in this lobular neoplasia, given the distribution of the lost probes, it is plausible we missed whole-arm loss in this case.

Further, there was no influence of concomitant neoplasia on the presence of copy number changes on chromosome 16q, implying that these losses are true carcinogenetic events and not just the result of field effects.

As expected and known from the literature our study did not find a smallest region of overlap or a hint towards the existence of specific tumour suppressor genes on 16q. Although, we found evidence for a breakpoint near the centromere, not previously described. In $65 \%$ of cases with whole-arm losses, the breakpoint was between VKORC1 and VPS35, and in $18 \%$ between $A B C C 12$ and CYLD. In three cases (atypical ductal hyperplasia, invasive ductal carcinoma grade 1 and ductal carcinoma in situ grade 3) with this breakpoint, there was gain of VPS35 and $A B C C 12$, making it unlikely that losses of $A B C C 12$ and VPS35 have a major role in low-grade breast carcinogenesis.

Gains of single probes on chromosome 16p were frequently seen but whole-arm gains were relatively rare. In addition, there was no relation between whole-arm gains on
$16 \mathrm{p}$ and progression in the low-grade breast neoplasia family. Previously, higher frequencies of $16 p$ gains were described in tubular carcinoma and invasive lobular carcinoma (39\% and 42-54\%, respectively) $[13,44,49,50]$. These differences can be explained by the fact we only included whole-arm gains and no partial arm gains and by the use of different (less specific) techniques before. Overall, our results implicate that $16 p$ does not have a major role in early low-grade breast carcinogenesis.

In cases with significant losses, not fulfilling the definition of whole-arm loss, the losses appeared to be spread fairly randomly across the whole $16 \mathrm{q}$ arm. Clear segmental loss in low-grade breast neoplasia was only found once in a ductal carcinoma in situ grade 1 . Thereby, no smallest regions of overlap were found, and no driver genes could be identified. This is in line with previous studies $[8,51,52]$. Therefore, the carcinogenetic effect of $16 q$ might be due to a multitude of mechanisms. Haploinsufficiency of genes residing on chromosome 16q has been shown to be of interest in the early steps of breast carcinogenesis [39]. However, the interpretation of these results is complicated by the finding that the copy number status of genes on $16 \mathrm{q}$ is not necessarily reflected on the protein expression level [53]. This is further sustained by findings of Rakha et al. [54] and Cleton-Jansen et al. [55] focussing on CTCF and NQO1. Noteworthy and in line with these findings, our study supports this missing effect. Of the atypical ductal hyperplasia cases with wholearm 16q losses, including the E-Cadherin locus, a normal membranous E-Cadherin expression could be observed in all investigated cases.

Also in invasive breast cancer, the loss of $16 q$ has repeatedly been shown to be associated with the gain of $1 \mathrm{q}$ [56] with a clear impact on the mRNA expression levels of the respective genes [39]. The interplay of these genes is completely unknown. A new perspective, complicating the present knowledge, has been added by the association of non-16q-located single-nucleotide polymorphisms associated with chromosomal 16q losses [57]. It therefore seems likely that a multitude of genes located on chromosome 16q, 1q or single-nucleotide polymorphisms associated with these alterations, with unknown interplay, contribute to the evolution of low-grade breast cancer, rather than major events in a few key genes.

In conclusion, columnar cell lesions (with and without atypia) often harbour whole-arm losses of $16 \mathrm{q}$, which emphasizes their role as precursors in low-grade breast carcinogenesis, in contrast with usual ductal hyperplasia and blunt duct adenosis. However, no recurrent losses in specific genes could be identified, pointing to minor events in multiple tumour suppressor genes rather than major events in a single $16 \mathrm{q}$ gene contributing to low-grade breast carcinogenesis. 


\section{Compliance with ethical standards}

Conflict of interest M Steenkamer and S Savola are employed by MRC-Holland, manufacturer of commercially available multiplex ligation-dependent probe amplification probe mixes. All other authors declare that they have no conflict of interest.

\section{References}

1. Fraser JL, Raza S, Chorny K, et al. Columnar alteration with prominent apical snouts and secretions: a spectrum of changes frequently present in breast biopsies performed for microcalcifications. Am J Surg Pathol. 1998;22:1521-7.

2. Schnitt SJ. The diagnosis and management of pre-invasive breast disease: flat epithelial atypia--classification, pathologic features and clinical significance. Breast Cancer Res. 2003;5:263-8.

3. Schnitt SJ, Vincent-Salomon A. Columnar cell lesions of the breast. Adv Anat Pathol. 2003;10:113-24.

4. Abdel-Fatah TM, Powe DG, Hodi Z, et al. Morphologic and molecular evolutionary pathways of low nuclear grade invasive breast cancers and their putative precursor lesions: further evidence to support the concept of low nuclear grade breast neoplasia family. Am J Surg Pathol. 2008;32:513-23.

5. Moinfar F, Man YG, Bratthauer GL, et al. Genetic abnormalities in mammary ductal intraepithelial neoplasia-flat type ("clinging ductal carcinoma in situ"): a simulator of normal mammary epithelium. Cancer. 2000;88:2072-81.

6. Simpson PT, Gale T, Reis-Filho JS, et al. Columnar cell lesions of the breast: the missing link in breast cancer progression? A morphological and molecular analysis. Am J Surg Pathol. 2005;29:734-46.

7. Buerger H, Otterbach F, Simon R, et al. Different genetic pathways in the evolution of invasive breast cancer are associated with distinct morphological subtypes. J Pathol. 1999;189:521-6.

8. Burger H, de Boer M, van Diest PJ, et al. Chromosome 16q loss-a genetic key to the understanding of breast carcinogenesis. Histol Histopathol. 2013;28:311-20.

9. Loo LW, Ton C, Wang YW, et al. Differential patterns of allelic loss in estrogen receptor-positive infiltrating lobular and ductal breast cancer. Genes Chromosomes Cancer. 2008;47:1049-66.

10. Riener MO, Nikolopoulos E, Herr A, et al. Microarray comparative genomic hybridization analysis of tubular breast carcinoma shows recurrent loss of the CDH13 locus on 16q. Hum Pathol. 2008;39:1621-9.

11. Roylance R, Gorman P, Hanby A, et al. Allelic imbalance analysis of chromosome 16q shows that grade I and grade III invasive ductal breast cancers follow different genetic pathways. J Pathol. 2002;196:32-36.

12. Roylance R, Gorman P, Papior T, et al. A comprehensive study of chromosome 16q in invasive ductal and lobular breast carcinoma using array CGH. Oncogene. 2006;25:6544-53.

13. Waldman FM, Hwang ES, Etzell J, et al. Genomic alterations in tubular breast carcinomas. Hum Pathol. 2001;32:222-6.

14. Buerger H, Otterbach F, Simon R, et al. Comparative genomic hybridization of ductal carcinoma in situ of the breast-evidence of multiple genetic pathways. J Pathol. 1999;187:396-402.

15. Etzell JE, Devries S, Chew K, et al. Loss of chromosome $16 \mathrm{q}$ in lobular carcinoma in situ. Hum Pathol. 2001;32:292-6.

16. Gao Y, Niu Y, Wang X, et al. Genetic changes at specific stages of breast cancer progression detected by comparative genomic hybridization. J Mol Med (Berl). 2009;87:145-52.

17. Green AR, Krivinskas S, Young P, et al. Loss of expression of chromosome $16 \mathrm{q}$ genes DPEP1 and CTCF in lobular carcinoma in situ of the breast. Breast Cancer Res Treat. 2009;113:59-66.
18. Lakhani SR, Collins N, Stratton MR, et al. Atypical ductal hyperplasia of the breast: clonal proliferation with loss of heterozygosity on chromosomes $16 \mathrm{q}$ and $17 \mathrm{p}$. J Clin Pathol. 1995; 48:611-5

19. Larson PS, de las Morenas A, Cerda SR, et al. Quantitative analysis of allele imbalance supports atypical ductal hyperplasia lesions as direct breast cancer precursors. J Pathol. 2006;209: 307-16.

20. Lu YJ, Osin P, Lakhani SR, et al. Comparative genomic hybridization analysis of lobular carcinoma in situ and atypical lobular hyperplasia and potential roles for gains and losses of genetic material in breast neoplasia. Cancer Res. 1998;58:4721-7.

21. Mastracci TL, Shadeo A, Colby SM, et al. Genomic alterations in lobular neoplasia: a microarray comparative genomic hybridization signature for early neoplastic proliferation in the breast. Genes Chromosomes Cancer. 2006;45:1007-17.

22. Vos CB, ter Haar NT, Rosenberg C, et al. Genetic alterations on chromosome 16 and 17 are important features of ductal carcinoma in situ of the breast and are associated with histologic type. $\mathrm{Br} \mathrm{J}$ Cancer. 1999;81:1410-8.

23. Aulmann S, Elsawaf Z, Penzel R, et al. Invasive tubular carcinoma of the breast frequently is clonally related to flat epithelial atypia and low-grade ductal carcinoma in situ. Am J Surg Pathol. 2009;33:1646-53.

24. Ellsworth RE, Ellsworth DL, Weyandt JD, et al. Chromosomal alterations in pure nonneoplastic breast lesions: implications for breast cancer progression. Ann Surg Oncol. 2010;17:1688-94.

25. Go EM, Tsang JY, Ni YB, et al. Relationship between columnar cell changes and low-grade carcinoma in situ of the breast--a cytogenetic study. Hum Pathol. 2012;43:1924-31.

26. Stacher E, Boldt V, Leibl S, et al. Chromosomal aberrations as detected by array-comparative genomic hybridization in early low-grade intraepithelial neoplasias of the breast. Histopathology. 2011;59:549-55.

27. Gomes DS, Porto SS, Balabram D, et al. Inter-observer variability between general pathologists and a specialist in breast pathology in the diagnosis of lobular neoplasia, columnar cell lesions, atypical ductal hyperplasia and ductal carcinoma in situ of the breast. Diagn Pathol. 2014;9:121.

28. Tan PH, Ho BC, Selvarajan S, et al. Pathological diagnosis of columnar cell lesions of the breast: are there issues of reproducibility? J Clin Pathol. 2005;58:705-9.

29. Ellis IO, Collins $\mathrm{C}$, Ichihara $\mathrm{S}$, et al. Invasive carcinoma of no special type. In: lakhani SR, Ellis IO, Schnitt SJ, et al., editors. WHO Classification of Tumours of the Breast. 4th ed. Lyon: International Agency for Research on Cancer (IARC); 2012. p. 34-38.

30. Lakhani SR, Rakha EA, Simpson PT. Invasive lobulair carcinoma. In: lakhani SR, Ellis IO, Schnitt SJ, et al., editors. WHO Classification of Tumours of the Breast. 4th ed. Lyon: International Agency for Research on Cancer (IARC); 2012. p. 40-42.

31. Schnitt SJ, Allred C, Britton P, et al. Ductal carcinoma in situ. In: lakhani SR, Ellis IO, Schnitt SJ, et al., editors. WHO Classification of Tumours of the Breast. 4th ed. Lyon: International Agency for Research on Cancer (IARC); 2012. p. 90-94.

32. Simpson JF, Schnitt SJ, Visscher D, et al. Atypcial ductal hyperplasia. In: lakhani SR, Ellis IO, Schnitt SJ, et al., editors. WHO Classification of Tumours of the Breast. 4th ed. Lyon: International Agency for Research on Cancer (IARC); 2012. p. $88-89$.

33. Collins L, Visscher D, Simpson J, et al. Usual ductal hyperplasia. In: lakhani SR, Ellis IO, Schnitt SJ, et al., editors. WHO Classification of Tumours of the Breast. 4th ed. Lyon: International Agency for Research on Cancer (IARC); 2012. p. 84-85. 
34. Lakhani SR, Schnitt SJ, O’Malley FP, et al. Lobular neoplasia. In: lakhani SR, Ellis IO, Schnitt SJ, et al., editors. WHO Classification of Tumours of the Breast. 4th ed. Lyon: International Agency for Research on Cancer (IARC); 2012. p. 78-80.

35. Lerwill MF. Flat epithelial atypia of the breast. Arch Pathol Lab Med. 2008;132:615-21.

36. Brogi E. Adenosis and Microglandular Adenosis. In: Hoda SA, Brogi E, Koerner F, et al., editors. Rosen's Breast Pathology. 4th ed. Philadelphia, PA: Lippincott Williams and Wilkins; 2014. p. 183-212.

37. van Diest PJ. No consent should be needed for using leftover body material for scientific purposes. For. BMJ. 2002;325:648-51.

38. Lacle MM, Kornegoor R, Moelans CB, et al. Analysis of copy number changes on chromosome $16 \mathrm{q}$ in male breast cancer by multiplex ligation-dependent probe amplification. Mod Pathol. 2013;26:1461-7.

39. Hungermann D, Schmidt H, Natrajan R, et al. Influence of whole arm loss of chromosome 16q on gene expression patterns in oestrogen receptor-positive, invasive breast cancer. J Pathol. 2011;224:517-28.

40. Rakha EA. The low nuclear grade breast neoplasia family. Diagn Histopathol. 2012;18:124-32.

41. Schouten JP, McElgunn CJ, Waaijer R, et al. Relative quantification of 40 nucleic acid sequences by multiplex ligationdependent probe amplification. Nucleic Acids Res. 2002; 30:e57.

42. Nowee ME, Snijders AM, Rockx DA, et al. DNA profiling of primary serous ovarian and fallopian tube carcinomas with array comparative genomic hybridization and multiplex ligationdependent probe amplification. J Pathol. 2007;213:46-55.

43. Moelans CB, de Weger RA, van Blokland MT, et al. HER-2/neu amplification testing in breast cancer by multiplex ligationdependent probe amplification in comparison with immunohistochemistry and in situ hybridization. Cell Oncol. 2009;31: $1-10$.

44. Lacroix-Triki M, Suarez PH, MacKay A, et al. Mucinous carcinoma of the breast is genomically distinct from invasive ductal carcinomas of no special type. J Pathol. 2010;222:282-98.

45. Turashvili G, Hayes M, Gilks B, et al. Are columnar cell lesions the earliest histologically detectable non-obligate precursor of breast cancer? Virchows Arch. 2008;452:589-98.
46. Shaaban AM, Sloane JP, West CR, et al. Histopathologic types of benign breast lesions and the risk of breast cancer: case-control study. Am J Surg Pathol. 2002;26:421-30.

47. Hanby AM, Ellis IO, Schnitt SJ. Columnar cell lesions. In: lakhani SR, Ellis IO, Schnitt SJ, et al., editors. WHO Classification of Tumours of the Breast. 4th ed. Lyon: International Agency for Research on Cancer (IARC); 2012. p. 86.

48. Kunju LP, Kleer CG. Significance of flat epithelial atypia on mammotome core needle biopsy: should it be excised? Hum Pathol. 2007;38:35-41.

49. Stange DE, Radlwimmer B, Schubert F, et al. High-resolution genomic profiling reveals association of chromosomal aberrations on 1q and 16p with histologic and genetic subgroups of invasive breast cancer. Clin Cancer Res. 2006;12:345-52.

50. Hwang ES, Nyante SJ, Yi Chen Y, et al. Clonality of lobular carcinoma in situ and synchronous invasive lobular carcinoma. Cancer. 2004;100:2562-72.

51. van Wezel T, Lombaerts M, van Roon EH, et al. Expression analysis of candidate breast tumour suppressor genes on chromosome 16q. Breast Cancer Res. 2005;7:R998-1004.

52. Rakha EA, Green AR, Powe DG, et al. Chromosome 16 tumorsuppressor genes in breast cancer. Genes Chromosomes Cancer. 2006;45:527-35.

53. Myhre S, Lingjaerde OC, Hennessy BT, et al. Influence of DNA copy number and mRNA levels on the expression of breast cancer related proteins. Mol Oncol. 2013;7:704-18.

54. Rakha EA, Pinder SE, Paish CE, et al. Expression of the transcription factor CTCF in invasive breast cancer: a candidate gene located at 16q22.1. Br J Cancer. 2004;91:1591-6.

55. Cleton-Jansen AM, van Eijk R, Lombaerts M, et al. ATBF1 and NQO1 as candidate targets for allelic loss at chromosome arm 16q in breast cancer: absence of somatic ATBF1 mutations and no role for the C609T NQO1 polymorphism. BMC Cancer. 2008;8:105.

56. Farabegoli F, Hermsen MA, Ceccarelli C, et al. Simultaneous chromosome 1q gain and $16 \mathrm{q}$ loss is associated with steroid receptor presence and low proliferation in breast carcinoma. Mod Pathol. 2004;17:449-55.

57. Nordgard SH, Johansen FE, Alnaes GI, et al. Genome-wide analysis identifies $16 \mathrm{q}$ deletion associated with survival, molecular subtypes, mRNA expression, and germline haplotypes in breast cancer patients. Genes Chromosomes Cancer. 2008;47:680-96. 